\title{
Design and analysis of application engineering talent cultivation based on AHP and QFD
}

\author{
Yanchun Xia \\ Shanghai Second Polytechnic University, Shanghai, 201209, China \\ ycxia@sspu.edu.cn
}

Keywords: Application talent, Talent Cultivation, AHP, QFD.

\begin{abstract}
Some issues in cultivating practice-oriented talents in higher education of the newly established local universities are addressed. Combined with the school-running mode, the orientation and the social requirement, the advanced manufacturing industry oriented application engineering talent cultivation mode was analyzed. The application engineering talent cultivation program is studied and established based on AHP and QFD. AHP can be used to confirm weight of voices of the customer in QFD. The designed cultivation program will satisfy stakeholder requirements and will improve the quality of graduates. The cultivation mode is practiced in SSPU and will spread to other specialties in future.
\end{abstract}

\section{Introduction}

With the developing of the IE4.0 and higher application talent cultivation, practice-oriented talents in engineering specialty is more and more important. At present, application engineering talent cultivation mode faced with several problem, including orientation, knowledge updating, practice ability inadequate, market adaptability and so on.

Students faced with fierce market competition, when they graduated. The figure 1 shows the competition factors based on Michael Porter's Five Forces Model. application engineering talents have some certain bargaining power as suppliers. But there are lots of new graduates and experienced relative persons enter the market. The current enterprise still hold the conservative views to relevant posts. So, application engineering talent cultivation competition improvement is very important, and the cultivation program

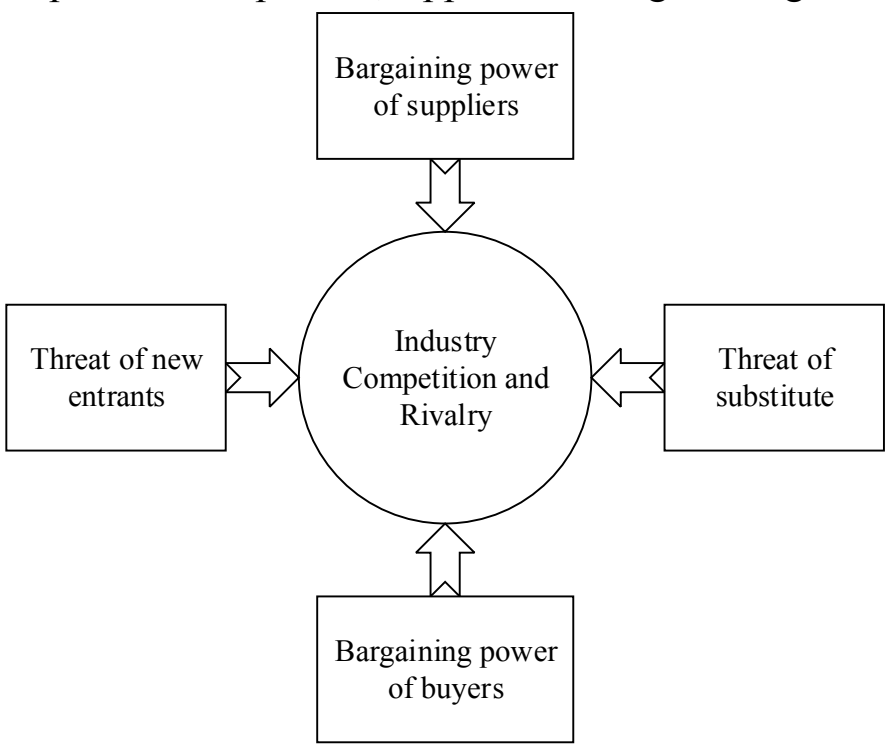

Fig.1 Five Forces Model is the basis of the talent cultivation.

\section{QFD and AHP}

Quality function deployment(QFD) is a production development method, which can translate the customer or market requirements into design targets. The main advantage of the QFD is when it analyzed and constructed the different layer elements, it can focus on the customer demand, key design and identify conflicts, shorten product development cycle and reduce the service cost. But using the traditional discrete scale 'strong, middle or weak' method to determine the weight of the customer needs is not enough, which can lead to the wrong analysis result.

Analytic hierarchy process(AHP) is a systematic decision making method which collates the relevant data and decision making into target layer, criteria layer, program level layer, etc. The main 
advantage of the method lies in using the quantitative data as little as possible, it can make the decision quickly and practically for multi-objective. But the AHP method can only make decisions in the existing schemes, cannot provide the new solution. If the selected elements is not reasonable, or the relationship between elements is not correct, it will lower the quality of the results of the AHP, and even cause the decision failure. In addition the commencement of the eigenvalue and eigenvector of the accurate calculation methods is more complex.

So, AHP and QFD methods are highly complementary in advantages and disadvantages. If using the complementary to design the talent cultivation program, it can exert great effects. Some studies have proposed the integration of AHP with QFD, where AHP's role would be to identify the priorities of the customer requirements and QFD would improve the decision making ${ }^{[1-4]}$.

Fig2 shows that it can identify the stakeholder's requirements, introduce competitive advantages and determine the weight of competitive advantages using AHP method, then using the result as the part of the QFD input to select and determine the important lean attributes on competitive advantages using QFD method. Based on QFD and AHP method, the cultivation program can be design and evaluation.

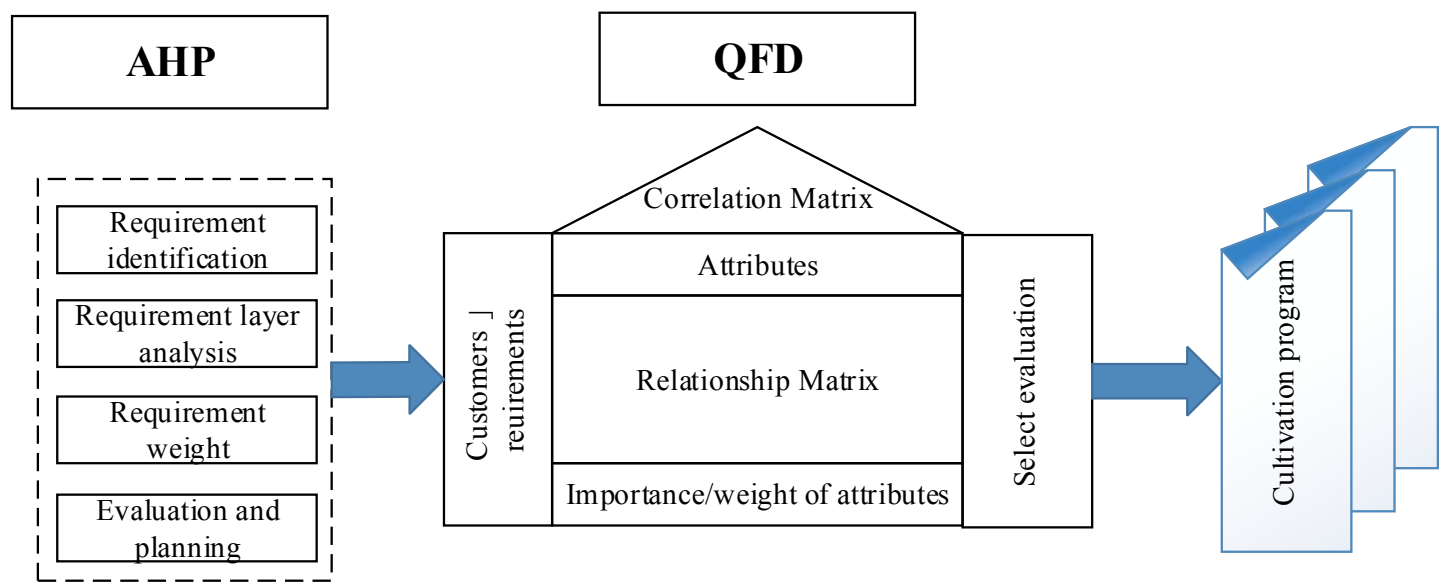

Fig.2 The flow chart of cultivation program design based on AHP and QFD

\section{AHP model}

Identifying the customers' requirements (CRs) in higher education is very difficult. The students, parents, faculty, employers, government and public are all the customers but have different requirement. How to design a cultivation program, which can make students apply knowledge and skills from college to worksite and have a sustainable competitive advantage as well, is a very important issue. Based on earlier studies, investigation and dislocation competition analysis, the customers' requirements and the competitive advantages are determined.

IE specialty is one of the key supporting specialties in advanced manufacturing industry. IE exerts more and more impacts on quality guarantee, productivity increasing, cost reduction, economic benefit promotion and enterprise whole competitiveness strengthening etc. IE is the bridge and link of the advanced manufacturing technology and advance management mode. The applied innovative talent cultivation of the IE specialty in applied undergraduate colleges and universities is the important approach to improve the employability from root to branch. According to our university talent cultivation feature, collect the information from the students, enterprises and some specialists, most our IE graduates were employed by manufacturing enterprise, and mainly responsible for production system optimization, quality management and flow analysis etc.

Hierarchy construction, priority analysis and consistency verification are the main three steps to establish the AHP model ${ }^{[5]}$. The first step of applying AHP in weighting the importance of CRs is to structure CRs into different hierarchy layers. Then based on the competitive advantages analysis, the 
weight of competitive advantages can be determined with AHP. Fig.3 is the IE requirement hierarchical model of IE specialty talent cultivation program.

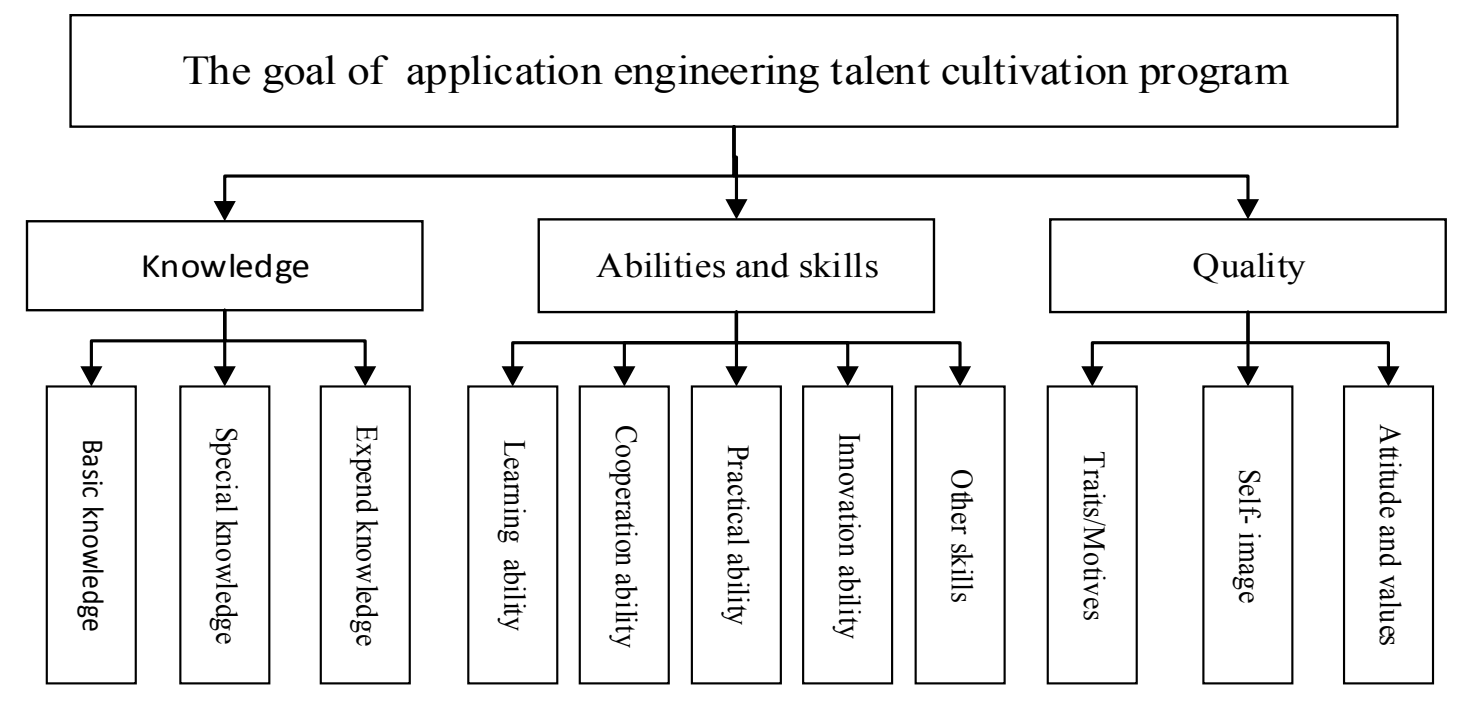

Fig.3 AHP model for the requirements of the IE talent cultivation

According to the requirements hierarchy of the knowledge, abilities, skills and quality of application engineering talent, using the T.L.Saaty's 1-9 scale method of evaluation of the indicators in different pair wise comparison, the structure comparison matrix A can be established.

$$
A=\left[\begin{array}{ccc}
a_{11} & \cdots & a_{1 n} \\
\vdots & \ddots & \vdots \\
a_{n 1} & \cdots & a_{n n}
\end{array}\right]
$$

Solving matrix to determine the characteristics of the root, find the largest eigenvalue $\lambda_{\max }$ and its corresponding feature vector $\boldsymbol{W}=\left(w_{1}, w_{2}, \ldots, w_{n}\right)^{T}, \prod_{n=1}^{n} w_{t}=1 . \mathrm{W}$ is the vector of the importance weighting determined by the AHP model.

$$
A \times W=\lambda_{\max } \times W
$$

Because small changes in $a_{i j}$ imply a small change in $\lambda_{\max }$, the deviation of the latter from $n$ is a measure of consistency. The consistency ratio is defined as

$$
\text { C.I. }=\left(\lambda_{\max }-n\right) /(n-1) \text { and C.R. }=\text { C.I./R.I. }
$$

In which R.I. are test values of average consistency, where $R . I .=0,0,0.52,0.89,1.12,1.26,1.36$, $1.41,1.46,1.49,1.52,1.54,1.56,1.58$ and 1.59 for the matrix order $n=1-15$. If $C . R . \leq 0.1$, the consistency verification is acceptable.

\section{QFD model}

application engineering talent cultivation program in our university mainly concerns the application and innovation cultivation based on engineering area knowledge. Talent cultivation system is reflected by the curriculum system and cultivation process. How to design the curriculum system, QFD is a very effective method ${ }^{[6]}$. The core of the QFD is the construction of the house of the quality. It needs to complete several steps, they are, specialty abilities requirements and importance weight computation, core courses determined, the relationship between abilities and courses, the relative matrix of courses, evaluation matrix and quality design etc. The ability and courses evaluated correlations of the relational matrix are expressed by symbols $\bullet, \circ$ and $\Delta$ indicate strong correlation, moderate correlation and weak correlation respectively and can be presented as 5, 3 and 1 to ensure 
that their differences can be effectively distinguished. The Fig.4 is the complete matrix example about the IE specialty, others specialties can be drawn at the same way.

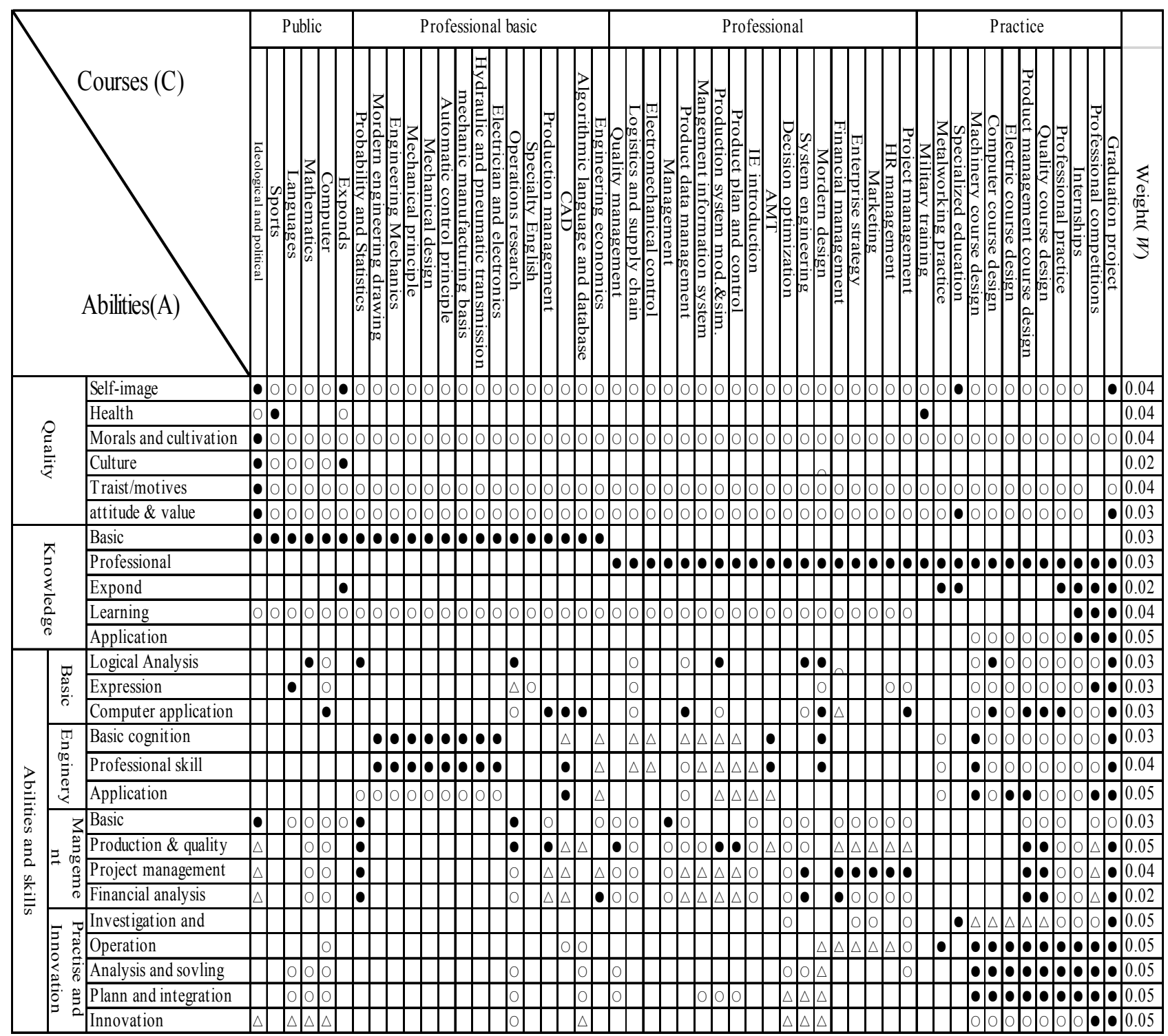

Fig.4 The QFD analysis example of IE cultivation program

For example, according to the ability requirement analysis of IE cultivation program, combine the investigation data, the relationships of abilities and courses are drawn, that is the relational matrix $\boldsymbol{R}_{i j}$ as shown in legend. Using above analysis of AHP, the $\boldsymbol{W}_{\boldsymbol{i}}$ can be computed. The $\boldsymbol{H}_{j}$ is the courses improvement importance, which was determined by multiplying the corresponding value in the matrix $\boldsymbol{R}_{i j}$ and the degree of importance of abilities $\boldsymbol{A}_{\boldsymbol{i}}$. That is

$$
H_{i}-\sum_{i=\mathrm{A}}^{m} W_{i} \mathrm{R}_{i f} \quad l-1_{i} z_{v} \cdots{ }_{z} \mathrm{TH}
$$

Then the courses were ranked according to their degree of importance based on their product values. So, the most important courses can be set as the core course for the cultivation program. At present, our IE specialty core courses are operation research, production planning and management, quality management, production system modeling and simulation, etc.

Based on the relationship of the courses, the credit, curriculum planning can be adjusted and the corresponding practice planning can be established. So with the change of CRs and the development of the knowledge and skills, the IE talent cultivation program and course system can be revised and improved. 


\section{Summary}

AHP and QFD are applied to talent cultivation program design for satisfying the CRs. Major CRs and competitiveness of application engineering area talent cultivation are identified by Five Forces Model. The AHP is proposed to weigh the CRs for talent cultivation program and course system design using QFD, which can provide the more accurate priority ranking of the CRs. The investigation, identification and analysis of importance of the CRs based on different talent cultivation goal is very important, because it can keep up the talent cultivation program with times, reflect education features and improve the cultivation quality.

\section{Acknowledgements}

The research work was supported by Shanghai Education Reform Projects under Grant No. A30DB1524013-04.

\section{References}

[1] Ho W, He T, Lee CKM, Emrouznejad A (2012) Strategic logistics outsourcing: an integrated QFD and fuzzy AHP approach. Expert Syst Appl 39:10841-10850

[2] Myint S (2003) A framework of an intelligent quality function deployment (IQFD) for discrete assembly environment. Comput Ind Eng 45(2):269-283

[3] Lin YH, Cheng HP, Tseng ML, Tsai CC (2010) Using QFD and ANP to analyze the environmental production requirements in linguistic preferences. Expert Syst Appl 37(3):2186-2196

[4] Wang YM, Chin KS (2011) Technical importance ratings in fuzzy QFD by integrating fuzzy normalization and fuzzy weighted average. Comput Math Appl 62(11):4207-4221

[5] Li Chengbiao. A study on teaching quality evaluation based on analytic hierarchy process. 2010 Sec. Int. workshop on education technology and computer science. 2010:449-452

[6] Wang Qiulian. Program design for industrial engineering education in China based on QFD. 2010 Sec. Int. workshop on education technology and computer science. 2010:333-336 